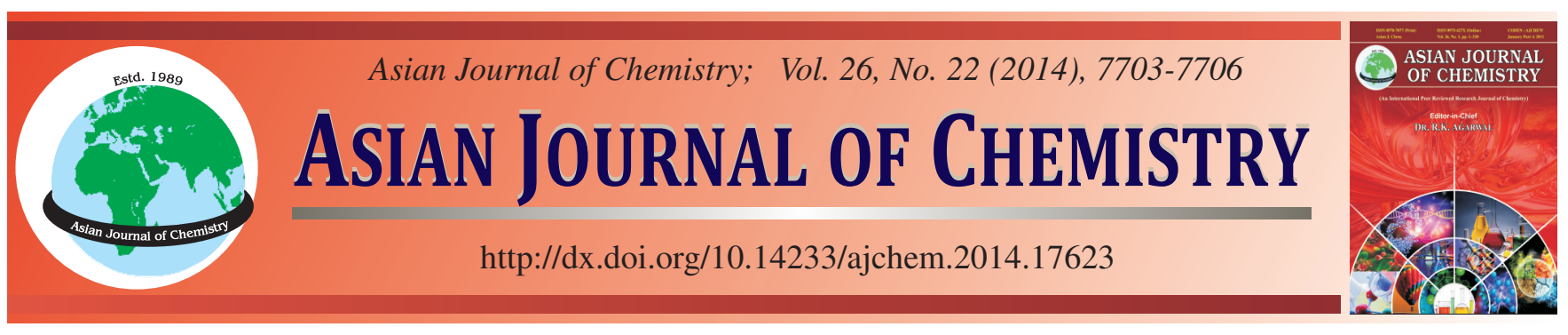

\title{
Synthesis, Characterization and Crystal Structures of Oxovanadium(V) Complexes with Benzohydrazone and 8-Hydroxyquinoline
}

\author{
Wei-Ming Zhang ${ }^{1, *}$, ShaO-Song Qian ${ }^{2}$ and Zhonglu You ${ }^{3}$
}

\author{
${ }^{1}$ Nanjing Institute for the Comprehensive Utilization of Wild Plant, Nanjing 210042, P.R. China \\ ${ }^{2}$ School of Life Sciences, Shandong University of Technology, Zibo 255049, P.R. China \\ ${ }^{3}$ Department of Chemistry and Chemical Engineering, Liaoning Normal University, Dalian 116029, P.R. China \\ *Corresponding author: E-mail: youzhonglu@126.com
}

\begin{abstract}
Two new oxovanadium $(\mathrm{V})$ complexes, $\left[\mathrm{VOL}^{1}(\mathrm{HQ})\right](\mathbf{1})$ and $\left[\mathrm{VOL}^{2}(\mathrm{HQ})\right](\mathbf{2})$, were prepared by the reaction of $\left[\mathrm{VO}(\mathrm{acac})_{2}\right](\mathrm{where}$ acac = acetylacetonate), 8-hydroxyquinoline (HHQ) with $N^{\prime}$-(5-fluoro-2-hydroxybenzylidene)-4-fluorobenzohydrazide $\left(\mathrm{H}_{2} \mathrm{~L}^{1}\right)$ and $N^{\prime}$-(5-fluoro2-hydroxybenzylidene)-4-methoxybenzohydrazide $\left(\mathrm{H}_{2} \mathrm{~L}^{2}\right)$, respectively, in methanol. Crystal and molecular structures of the complexes were determined by elemental analysis, infrared and UV-visible spectra and single crystal X-ray diffraction. Complex $\mathbf{1}$ crystallizes in the orthorhombic space group Pbcn, with unit cell dimensions a = 32.327(2) $\AA, \mathrm{b}=8.189(2) \AA, \mathrm{c}=16.817(1) \AA, \mathrm{V}=4451.9(9) \AA^{3}, \mathrm{Z}=8$, $\mathrm{GOOF}=1.060, \mathrm{R}_{1}=0.0587$ and $w \mathrm{R}_{2}=0.0921$. Complex 2 crystallizes in the monoclinic space group $\mathrm{P} 2_{1} / \mathrm{n}$, with unit cell dimensions a $=12.4965(8) \AA, b=13.3795(9) \AA, c=13.8324(9) \AA, \beta=115.555(2)^{\circ}, V=2086.5(2) \AA^{3}, Z=4, G O O F=1.047, R_{1}=0.0378$ and $w R_{2}=$ 0.0919. The $\mathrm{V}$ atoms in the complexes are in octahedral coordination, with the phenolate oxygen, imino nitrogen and enolate oxygen of the benzohydrazone ligand and the hydroxy oxygen of 8-hydroxyquinoline in the equatorial plane and with the pyridine nitrogen of 8hydroxyquinoline and one oxo group in the two axial positions. Thermal stability of the complexes was also studied.
\end{abstract}

Keywords: Benzohydrazone ligand, 8-Hydroxyquinoline, Oxovanadium complex, Crystal structure, Thermal property.

\section{INTRODUCTION}

Metal complexes with hydrazones have been received particular attention in biological and medicinal chemistry ${ }^{1-4}$. In recent years, vanadium complexes have been reported to have interesting biological activities such as normalizing the high blood glucose levels and acting as models of haloperoxidases $^{5-9}$. Recently, our research group has reported a few vanadium complexes with biological activities ${ }^{10-12} \cdot 8$-Hydroxyquinoline (HHQ) is a widely known bidentate ligand in coordination chemistry ${ }^{13-16}$, however, only two HQ coordinated oxovanadium complexes with hydrazone ligands have been reported so $\operatorname{far}^{17,18}$. In the present paper, two new oxovanadium(V) complexes with hydrazone and HQ ligands, $\left[\operatorname{VOL}^{1}(\mathrm{HQ})\right](\mathbf{1})$ and $\left[\mathrm{VOL}^{2}(\mathrm{HQ})\right](2)\left(\mathrm{H}_{2} \mathrm{~L}^{1}=N^{\prime}\right.$-(5-fluoro-2-hydroxybenzylidene)-4-fluorobenzohydrazide, $\mathrm{H}_{2} \mathrm{~L}^{2}=N^{\prime}$-(5-fluoro-2hydroxybenzylidene)-4-methoxybenzohydrazide; Scheme-I), have been presented.<smiles>[X]c1ccc(C(=O)N/N=C/c2cc(F)ccc2O)cc1</smiles>

Scheme-I: Benzohydrazone ligands. $\mathrm{H}_{2} \mathrm{~L}^{1}: \mathrm{X}=\mathrm{F} ; \mathrm{H}_{2} \mathrm{~L}^{2}: \mathrm{X}=\mathrm{OMe}$

\section{EXPERIMENTAL}

Commercially available 5-fluorosalicylaldehyde, 4fluorobenzohydrazide and 4-methoxybenzohydrazide were purchased from Sigma-Aldrich and used without further purification. Other solvents and reagents were made in China and used as received. $\mathrm{H}_{2} \mathrm{~L}^{1}$ and $\mathrm{H}_{2} \mathrm{~L}^{2}$ were prepared according to the literature method ${ }^{19,20}$. C, $\mathrm{H}$ and $\mathrm{N}$ elemental analyses were performed with a Perkin-Elmer elemental analyser. Infrared spectra were recorded on a Nicolet AVATAR 360 spectrometer as $\mathrm{KBr}$ pellets in the (4000-400) $\mathrm{cm}^{-1}$ region. UV-visible spectra were recorded on a Lambda 900 spectrometer with acetonitrile as the solvent. Thermal stability analysis was performed on a Perkin-Elmer Pyris Diamond TGA-DTA thermal analyses system.

Synthesis of [VOL $\left.{ }^{1}(\mathrm{HQ})\right](1)$ : A methanolic solution $(10 \mathrm{~mL})$ of $\left[\mathrm{VO}(\mathrm{acac})_{2}\right](0.1 \mathrm{mmol}, 26.5 \mathrm{mg})$ was added to a methanolic solution $(10 \mathrm{~mL})$ of $\mathrm{H}_{2} \mathrm{~L}^{1}(0.1 \mathrm{mmol}, 27.6 \mathrm{mg})$ and 8-hydroxyquinoline $(0.1 \mathrm{mmol}, 14.5 \mathrm{mg})$ with stirring. The mixture was stirred for $0.5 \mathrm{~h}$ at room temperature to give a deep brown solution. The resulting solution was allowed to stand in air for a few days. Brown block-shaped crystals suitable for $\mathrm{X}$-ray single crystal diffraction were formed at the bottom of 
the vessel. The isolated products were washed three times with cold methanol and dried in air. Yield: $55 \%$; Anal. Calcd. for $\mathrm{C}_{24} \mathrm{H}_{17} \mathrm{FN}_{3} \mathrm{O}_{5} \mathrm{~V}: \mathrm{C}, 58.0 ; \mathrm{H}, 3.4 ; \mathrm{N}$, 8.4. Found: C, 57.7; H, 3.5; $\mathrm{N}, 8.6 \%$.

Synthesis of [VOL $2(H Q)](2)$ : This complex was prepared according to the same method as that described for $\mathbf{1}$, with $\mathrm{H}_{2} \mathrm{~L}^{1}$ replaced by $\mathrm{H}_{2} \mathrm{~L}^{2}(0.1 \mathrm{mmol}, 28.8 \mathrm{mg})$. Yield: $45 \%$; Anal. Calcd. for $\mathrm{C}_{23} \mathrm{H}_{14} \mathrm{~F}_{2} \mathrm{~N}_{3} \mathrm{O}_{4} \mathrm{~V}$ : C, 56.9; H, 2.9; N, 8.7. Found: C, $56.8 ; \mathrm{H}, 2.9 ; \mathrm{N}, 8.5 \%$.

X-ray crystallography: Diffraction intensities for the complexes were collected at 298(2) K using a Bruker D8 VENTURE PHOTON diffractometer with $\mathrm{MoK}_{\alpha}$ radiation $(\lambda$ $=0.71073 \AA$ ). The collected data were reduced using the SAINT program $^{21}$, and multi-scan absorption corrections were performed using the SADABS program ${ }^{22}$. The structures were solved by direct methods and refined against $\mathrm{F}^{2}$ by full-matrix least-squares methods using the SHELXTL ${ }^{23}$. All of the nonhydrogen atoms were refined anisotropically. $\mathrm{H}$ atoms were placed in idealized positions and constrained to ride on their parent atoms. Crystallographic data are listed in Table-1. Selected bond lengths and angles are given in Table-2.

\begin{tabular}{|c|c|c|}
\hline \multicolumn{3}{|c|}{$\begin{array}{c}\text { TABLE-1 } \\
\text { CRYSTALLOGRAPHIC AND EXPERIMENTAL } \\
\text { DATA FOR } 1 \text { AND } 2\end{array}$} \\
\hline Complex & 1 & 2 \\
\hline m.f. & $\mathrm{C}_{24} \mathrm{H}_{17} \mathrm{FN}_{3} \mathrm{O}_{5} \mathrm{~V}$ & $\mathrm{C}_{23} \mathrm{H}_{14} \mathrm{~F}_{2} \mathrm{~N}_{3} \mathrm{O}_{4} \mathrm{~V}$ \\
\hline m.w. & 497.35 & 485.31 \\
\hline $\mathrm{T}(\mathrm{K})$ & $298(2)$ & $298(2)$ \\
\hline Crystal shape/color & Block/deep brown & Block/deep brown \\
\hline Crystal size $\left(\mathrm{mm}^{3}\right)$ & $0.30 \times 0.30 \times 0.27$ & $0.29 \times 0.26 \times 0.22$ \\
\hline Crystal system & Orthorhombic & Monoclinic \\
\hline Space group & Pben & $\mathrm{P}_{1} / \mathrm{n}$ \\
\hline $\mathrm{a}(\AA)$ & $32.327(2)$ & $12.4965(8)$ \\
\hline $\mathrm{b}(\AA)$ & $8.189(2)$ & $13.3795(9)$ \\
\hline c $(\AA)$ & $16.817(1)$ & $13.8324(9)$ \\
\hline$\alpha\left({ }^{\circ}\right)$ & 90 & 90 \\
\hline$\beta\left(\left(^{\circ}\right)\right.$ & 90 & $115.555(2)$ \\
\hline$\gamma\left({ }^{\circ}\right)$ & 90 & 90 \\
\hline$V\left(\AA^{3}\right)$ & $4451.9(9)$ & $2086.5(2)$ \\
\hline Z & 8 & 4 \\
\hline $\mathrm{D}_{\mathrm{c}}\left(\mathrm{g} \mathrm{cm}^{-3}\right)$ & 1.484 & 1.545 \\
\hline$\mu\left(\mathrm{MoK}_{\alpha}\right)\left(\mathrm{mm}^{-1}\right)$ & 0.496 & 0.530 \\
\hline $\mathrm{F}(000)$ & 2032 & 984 \\
\hline Measured reflections & 39935 & 20074 \\
\hline Independent reflections & 3956 & 3886 \\
\hline $\begin{array}{l}\text { Observed reflections }(\mathrm{I} \geq \\
2 \sigma(\mathrm{I}))\end{array}$ & 2075 & 2919 \\
\hline $\begin{array}{l}\text { Min. and max. } \\
\text { transmission }\end{array}$ & 0.8655 and 0.8778 & 0.8614 and 0.8923 \\
\hline Parameters & 308 & 298 \\
\hline Restraints & 0 & 0 \\
\hline Goodness-of-fit on $\mathrm{F}^{2}$ & 1.060 & 1.047 \\
\hline $\mathrm{R}_{1}, \mathrm{wR}_{2}[\mathrm{I} \geq 2 \sigma(\mathrm{I})]^{\mathrm{a}}$ & $0.0587,0.0921$ & $0.0378,0.0919$ \\
\hline $\mathrm{R}_{1}, \mathrm{wR}_{2}$ (all data) ${ }^{\mathrm{a}}$ & $0.1460,0.1168$ & $0.0592,0.1039$ \\
\hline $\begin{array}{l}\text { Largest peak and deepest } \\
\text { hole }\left(\mathrm{e} \AA^{-3}\right)\end{array}$ & $0.212,-0.223$ & $0.247,-0.260$ \\
\hline
\end{tabular}

\section{RESULTS AND DISCUSSION}

Replacement of two acetylacetonate ligands of [ $\left.\mathrm{VO}(\mathrm{acac})_{2}\right]$ by benzohydrazone and 8-hydroxyquinoline ligands in methanol resulted in the formation of two structurally similar complexes.

\begin{tabular}{|c|c|c|c|}
\hline \multicolumn{4}{|c|}{$\begin{array}{c}\text { TABLE-2 } \\
\text { SELECTED BOND DISTANCES }(\AA) \\
\text { AND ANGLES }\left({ }^{\circ}\right) \text { FOR THE COMPLEXES }\end{array}$} \\
\hline \multicolumn{4}{|c|}{ Complex 1} \\
\hline \multicolumn{4}{|c|}{ Bond lengths, $\AA$} \\
\hline V1-O1 & $1.856(2)$ & $\mathrm{V} 1-\mathrm{O} 2$ & $1.930(2)$ \\
\hline V1-O4 & $1.839(2)$ & V1-O5 & $1.582(3)$ \\
\hline V1-N1 & $2.077(3)$ & V1-N3 & $2.346(3)$ \\
\hline \multicolumn{4}{|c|}{ Bond angles, ${ }^{\circ}$} \\
\hline O5-V1-O4 & $99.82(12)$ & O5-V1-O1 & $99.32(12)$ \\
\hline O4-V1-O1 & $103.34(11)$ & $\mathrm{O} 5-\mathrm{V} 1-\mathrm{O} 2$ & $100.27(12)$ \\
\hline $\mathrm{O} 4-\mathrm{V} 1-\mathrm{O} 2$ & $91.60(10)$ & $\mathrm{O} 1-\mathrm{V} 1-\mathrm{O} 2$ & $152.88(11)$ \\
\hline O5-V1-N1 & $97.00(13)$ & O4-V1-N1 & $159.98(12)$ \\
\hline O1-V1-N1 & $84.46(11)$ & $\mathrm{O} 2-\mathrm{V} 1-\mathrm{N} 1$ & $74.71(11)$ \\
\hline O5-V1-N3 & $175.98(12)$ & O4-V1-N3 & $76.20(11)$ \\
\hline O1-V1-N3 & $81.22(11)$ & $\mathrm{O} 2-\mathrm{V} 1-\mathrm{N} 3$ & $80.55(10)$ \\
\hline N1-V1-N3 & 87.01(11) & - & - \\
\hline \multicolumn{4}{|c|}{ Complex 2} \\
\hline \multicolumn{4}{|c|}{ Bond lengths, $\AA$} \\
\hline V1-O1 & $1.8497(18)$ & $\mathrm{V} 1-\mathrm{O} 2$ & $1.9427(16)$ \\
\hline V1-O3 & $1.8304(15)$ & V1-O4 & $1.5879(16)$ \\
\hline V1-N1 & $2.0860(18)$ & V1-N3 & $2.3577(18)$ \\
\hline \multicolumn{4}{|c|}{ Bond angles, $^{\circ}$} \\
\hline $\mathrm{O} 4-\mathrm{V} 1-\mathrm{O} 3$ & $101.21(8)$ & O4-V1-O1 & $100.12(9)$ \\
\hline O3-V1-O1 & $102.23(7)$ & $\mathrm{O} 4-\mathrm{V} 1-\mathrm{O} 2$ & $97.90(8)$ \\
\hline $\mathrm{O} 3-\mathrm{V} 1-\mathrm{O} 2$ & $92.03(7)$ & $\mathrm{O} 1-\mathrm{V} 1-\mathrm{O} 2$ & $154.29(7)$ \\
\hline O4-V1-N1 & $98.03(8)$ & O3-V1-N1 & $158.13(7)$ \\
\hline O1-V1-N1 & $84.39(7)$ & O2-V1-N1 & $75.02(7)$ \\
\hline O4-V1-N3 & $175.40(9)$ & O3-V1-N3 & 76.31(6) \\
\hline O1-V1-N3 & $84.25(7)$ & $\mathrm{O} 2-\mathrm{V} 1-\mathrm{N} 3$ & 78.43(6) \\
\hline N1-V1-N3 & $83.75(6)$ & - & - \\
\hline
\end{tabular}

The complexes are soluble in DMF, DMSO, methanol, ethanol and acetonitrile. Molar conductance of the complexes at the concentrations of $10^{-4} \mathrm{~mol} \mathrm{~L}^{-1}$ are in the range $20-35 \Omega^{-1} \mathrm{~cm}^{2}$ $\mathrm{mol}^{-1}$, indicating they are non-electrolytes ${ }^{24}$.

Crystal structure description of the complexes: The molecular structures and atom numbering schemes of complexes $\mathbf{1}$ and $\mathbf{2}$ are shown in Figs. 1 and 2, respectively. Vanadium atoms in the complexes are in octahedral coordination, with the three donor atoms of the benzohydrazone ligands and the hydroxy $\mathrm{O}$ atom of the HQ ligand defining the equatorial plane and with one oxo $\mathrm{O}$ atom and the pyridine $\mathrm{N}$ atom of the 8hydroxyquinoline ligand occupying the axial positions. The distances between atoms $\mathrm{V} 1$ and $\mathrm{O} 5$ in $\mathbf{1}$ and V1 and $\mathrm{O} 4$ in $\mathbf{2}$ are $1.58(2) \AA$, indicating they are typical $\mathrm{V}=\mathrm{O}$ double bonds. The $\mathrm{V}-\mathrm{N}_{\text {pyridine }}$ bonds in the complexes are significantly longer than the other coordinate bonds, yet, it is not uncommon for such complexes ${ }^{17,18}$. The bond lengths in both complexes are comparable to each other and also similar to those observed in the mononuclear oxovanadium(V) complexes with octahedral coordination ${ }^{17,18}$. The angular distortion in the octahedral environment around vanadium comes from the five- and sixmembered chelate rings taken by the benzohydrazone ligands. For the same reason, the trans angles significantly deviate from the ideal values of $180^{\circ}$. Distortion of the octahedral coordination can be observed from the coordinate bond angles, ranging from $74.71(11)^{\circ}$ to $103.34(11)^{\circ}$ for the perpendicular angles and from $152.88(12)^{\circ}$ to $175.98(12)^{\circ}$ for the diagonal angles for 1 and from $75.02(7)^{\circ}$ to $102.23(7)^{\circ}$ for the perpendicular angles and from $154.29(7)^{\circ}$ to $175.40(9)^{\circ}$ for the diagonal angles for $\mathbf{2}$. The displacement of the vanadium atoms from 
the equatorial plane are 0.305(1) $\AA$ for $\mathbf{1}$ and $0.315(1) \AA$ for 2.

The dihedral angles between the two benzene rings of the benzohydrazone ligands are $16.7(3)^{\circ}$ in $\mathbf{1}$ and 5.5(3) in $\mathbf{2}$.

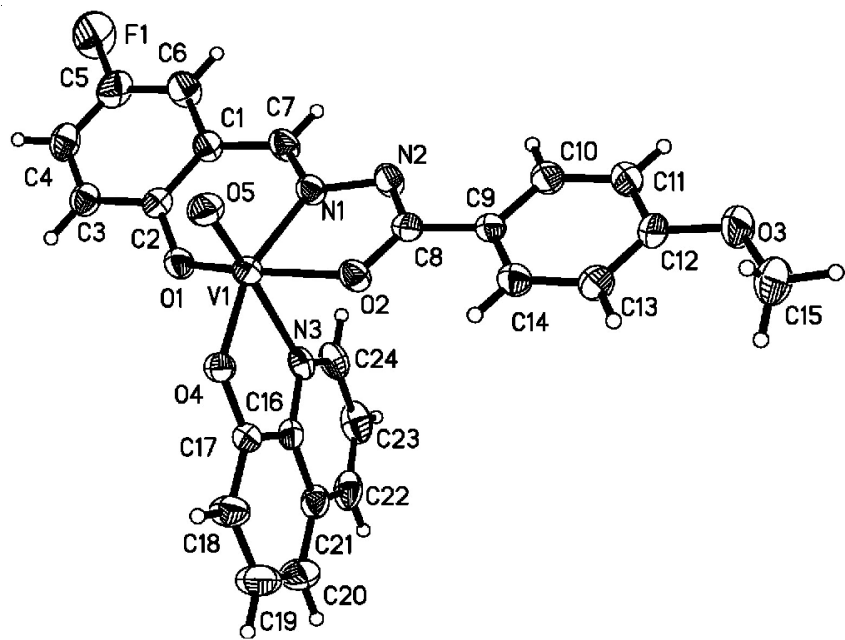

Fig. 1. ORTEP plot of the molecular structure of $\mathbf{1}$. Displacement ellipsoids of non-hydrogen atoms are drawn at the $30 \%$ probability level



Fig. 2. ORTEP plot of the molecular structure of 2. Displacement ellipsoids of non-hydrogen atoms are drawn at the $30 \%$ probability level

IR and UV-visible spectra: Complexes $\mathbf{1}$ and $\mathbf{2}$ exhibit typical bands at 970 and $973 \mathrm{~cm}^{-1}$, respectively, assigned to the $\mathrm{V}=\mathrm{O}$ vibration ${ }^{9 \mathrm{~b}}$. The bands due to $\mathrm{v}_{\mathrm{C}=\mathrm{O}}$ were absent in the complexes, but new $\mathrm{C}-\mathrm{O}$ stretches appeared at $1257 \mathrm{~cm}^{-1}$ for $\mathbf{1}$ and 2 . This suggests occurrence of keto-imine tautomerization of the ligands during complexation. The intense $v \mathrm{C}=\mathrm{N}$ absorptions are observed at $1605 \mathrm{~cm}^{-1}$ for 1 and $1610 \mathrm{~cm}^{-1}$ for 2. The weak peaks in the low wave numbers in the region $(650-450) \mathrm{cm}^{-1}$ may be attributed to $\mathrm{V}-\mathrm{O}$ and $\mathrm{V}-\mathrm{N}$ bonds in the complexes.

The acetonitrile solutions of the complexes with concentration of $10^{-5} \mathrm{~mol} \mathrm{~L}^{-1}$ have been used to record the electronic spectra. The main features of all the spectra are quite similar (Fig. 3). There are two major absorptions within the ranges $650-450$ and $360-320 \mathrm{~nm}$ in the visible region. These are attributed to the ligand-to-metal charge transfer transitions (LMCT). The high energy absorptions (300-220 nm) are most likely due to the transition involving ligand orbitals only.

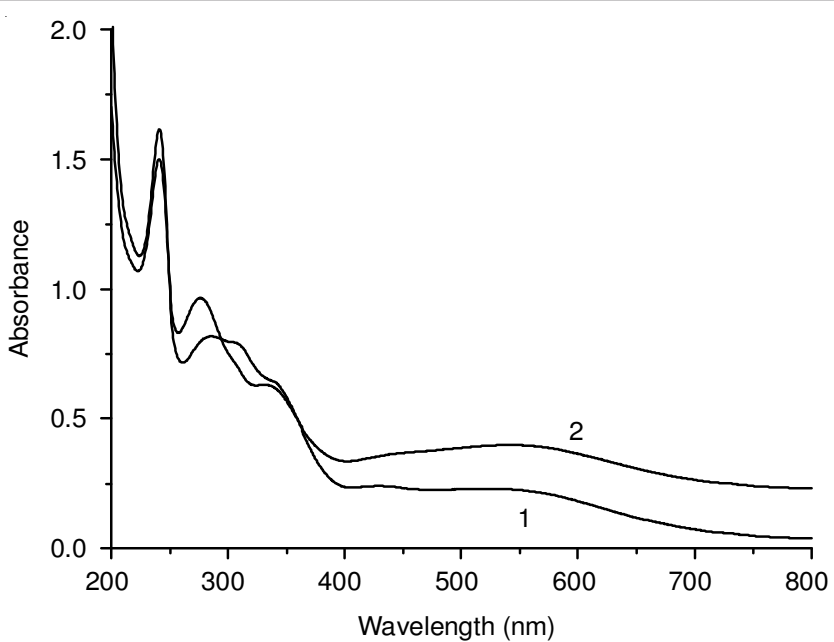

Fig. 3. UV-visible spectra of the VO(II) complexes

Thermal property: Differential thermal and thermal gravimetric analyses were conducted to examine the stability of the complexes under air atmosphere and with standard corundum crucible sample holder (Fig. 4 for $\mathbf{1}$ and Fig. 5 for 2). The rate of the gas flow is $20 \mathrm{~cm}^{3} \mathrm{~min}^{-1}$. The heating rate is $\left.10{ }^{\circ} \mathrm{C} \mathrm{min}^{-1}\right)$. For $\mathbf{1}$, the complex decomposed from 240 to 520 ${ }^{\circ} \mathrm{C}$, corresponding to the loss of the benzohydrazone and HQ ligands and the formation of $\mathrm{V}_{2} \mathrm{O}_{5}$. The total observed weight

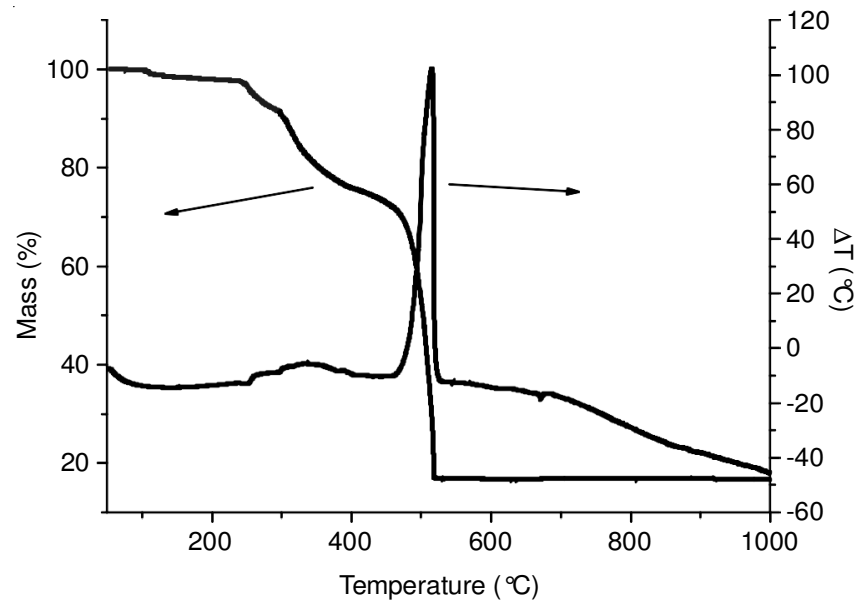

Fig. 4. DTA-TGA curve of complex 1

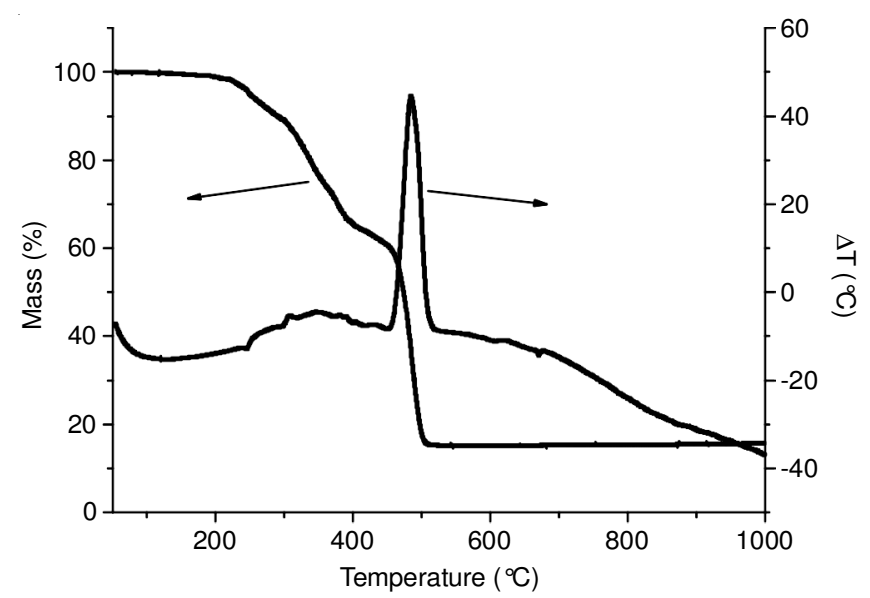

Fig. 5. DTA-TGA curve of complex 2 
loss of $83 \%$ is close to the calculated value of $81.7 \%$. For complex 2, the complex decomposed from 200 to $520{ }^{\circ} \mathrm{C}$, corresponding to the loss of the benzohydrazone and HQ ligands and the formation of $\mathrm{V}_{2} \mathrm{O}_{5}$. The total observed weight loss of $83.5 \%$ is close to the calculated value of $81.3 \%$.

Supporting information: CCDC 991929 for 1 and CCDC 991930 for 2 contain the supplementary crystallographic data for this paper. These data can be obtained free of charge at http://www.ccdc.cam.ac.uk/const/retrieving.html or from the Cambridge Crystallographic Data Centre (CCDC), 12 Union Road, Cambridge CB2 1EZ, UK; fax: +44(0)1223-336033 or e-mail: deposit@ccdc.cam.ac.uk.

\section{REFERENCES}

1. M.F. Wang, Z.Y. Yang, Y. Li and H.G. Li, J. Coord. Chem., 64, 2974 (2011).

2. A. El-Dissouky, O. Al-Fulaij, M.K. Awad and S. Rizk, J. Coord. Chem., 63, 330 (2010).

3. K.M. Ibrahim, I.M. Gabr and R.R. Zaky, J. Coord. Chem., 62, 1100 (2009).

4. A.S. El-Tabl, F.A. El-Saied and A.N. Al-Hakimi, J. Coord. Chem., 61, 2380 (2008)

5. P. Caravan, L. Gelmini, N. Glover, F.G. Herring, H.L. Li, J.H. McNeill, S.J. Rettig, I.A. Setyawati, E. Shuter and Y. Sun, J. Am. Chem. Soc., 117, 12759 (1995).

6. A.A. Nejo, G.A. Kolawole, A.R. Opoku, C. Muller and J. Wolowska, J. Coord. Chem., 62, 3411 (2009).

7. A. Messerschmidt, L. Prade and R. Wever, Biol. Chem., 378, 309 (1997).
8. R. Ara, U. Ashiq, M. Mahroof-Tahir, Z.T. Maqsood, K.M. Khan, M.A. Lodhi and M.I. Choudhary, Chem. Biodivers., 4, 58 (2007).

9. M.A.S. Aslam, S. Mahmood, M. Shahid, A. Saeed and J. Iqbal, Eur. J. Med. Chem., 46, 5473 (2011).

10. Z.-L. You, D.-H. Shi, J.-C. Zhang, Y.-P. Ma, C. Wang and K. Li, Inorg. Chim. Acta, 384, 54 (2012).

11. Z.-L. You, H. Sun, B.-W. Ding, Y.-P. Ma, M. Zhang and D.-M. Xian, J. Coord. Chem., 64, 3510 (2011).

12. Z.-P. Xiao, Z.-Y. Peng, J.-J. Dong, R.-C. Deng, X.-D. Wang, H. Ouyang, P. Yang, J. He, Y.-F. Wang and M. Zhu, Eur. J. Med. Chem., 68, 212 (2013).

13. T.G. Barros, J.S. Williamson, O.A.C. Antunes and E.M.F. Muri, Lett. Drug Des. Discov., 6, 186 (2009).

14. A.F.A. Peacock, S. Parsons and P.J. Sadler, J. Am. Chem. Soc., 129, 3348 (2007).

15. T. Birk and J. Bendix, Inorg. Chem., 42, 7608 (2003).

16. H.M. Colquhoun, D.J. Williams and Z.X. Zhu, J. Am. Chem. Soc., 124, 13346 (2002).

17. Z.-P. Deng, S. Gao, H. Zhao and L.-H. Huo, Chinese J. Inorg. Chem., 23, 173 (2007).

18. T. Ghosh, B. Mondal, T. Ghosh, M. Sutradhar, G. Mukherjee and M.G.B. Drew, Inorg. Chim. Acta, 360, 1753 (2007).

19. V.S. Sergienko, V.L. Abramenko, L.K. Minacheva, M.A. Poraikoshits and V.G. Sakharova, Russ. J. Coord. Chem., 19, 28 (1993).

20. J.C. Cui, H.D. Yin and Y.L. Qiao, Acta Crystallogr. Sect. E Struct. Rep. Online, 63, o2633 (2007).

21. Bruker, SMART and SAINT. Bruker AXS Inc., Madison, Wisconsin, USA (2002).

22. G.M. Sheldrick, SADABS. Program for Empirical Absorption Correction of Area Detector, University of Göttingen, Germany (1996)

23. G.M. Sheldrick, Acta Crystallogr. A, 64, 112 (2008).

24. W.J. Geary, Coord. Chem. Rev., 7, 81 (1971). 